\title{
A Prototype Simplified Daylighting Design Tool
}

Stephen J. Treado

Peter J. Goodin

Building and Fire Research Laboratory

Gaithersburg, Maryland 20899

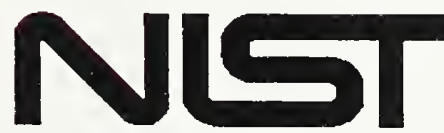

- QC__ ates Department of Commerce sy Administration

100 nstitute of Standards and Technology

.456 



\section{A Prototype Simplified Daylighting Design Tool}

Stephen J. Treado

Peter J. Goodin

July 1992

Building and Fire Research Laboratory

National Institute of Standards and Technology

Gaithersburg, MD 20899

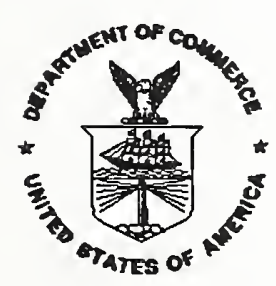

U.S. Department of Commerce

Barbard Hackman Franklin, Secretary

Technology Administration

Robert M. White, Under Secretary for Technology

National Institute of Standards and Technology

John W. Lyons, Director 
This report describes a prototype simplified design tool which has been developed to provide information for developing effective building fenestration systems. A computer software system was developed to search through and select the best available fenestration designs from a large database of previously simulated buildings. Fenestration designs can be selected based on energy usage, energy cost or peak loads. The determination of fenestration energy costs is discussed. The design tool is primarily intended for commercial, industrial or institutional buildings of any type.

Keywords: building design, clerestories, fenestration, lighting, skylights, windows

Disclaimer: Any commercial products, materials or equipment referenced in this document are done so for information only, and no endorsement or recommendation is implied. 
Table of Contents

1. Introduction .. . . . . . . . . . . . . . . . . . . . 1

2. Fenestration Performance Trade-offs . . . . . . . . . . . . . . . 1

3. Determining Optimum Fenestration Design . . . . . . . . . . . . . . 2

4. Using the Design Tool. . . . . . . . . . . . . . . . . . . 6

5. Conclusions . . . . . . . . . . . . . . . . . . . . . . 8

6. References ... . . . . . . . . . . . . . . . . . . . . . 8 


\section{List of Figures}

Figure 1 Screen one of the daylighting design tool. . . . . . . . . . 10

Figure 2 Screen two of the daylighting design tool. . . . . . . . . . 11

Figure 3 Screen three of the daylighting design tool. . . . . . . . . 12

Figure 4 Sample results from design session for Norfolk, minimum total energy . . . . . . . . . . . . . . . . . . . . . . 13

Figure 5 Sample results for Norfolk, minimum cooling energy . . . . . 14

Figure 6 Sample results for Norfolk, north sawtooth, minimum total 15 
Table 1

Table 2

Table 3
Summary of Building Simulation Parameters . . . . . . . . . .

Fenestration Performance Values . . . . . . . . . . . . . . . Heating and Cooling Degree Days for Geographical Locations in Knowledge Base 


\section{Introduction}

Daylighting in buildings refers to the use of fenestration systems to admit natural light to interior spaces. The daylight can be used to supplement electric lighting, meet the needs of building occupants, indoor plants and vegetation, or enhance the aesthetic qualities of the building interior. The beneficial energy performance of daylighting has been well-documented, and derives primarily from a reduction in lighting energy requirements [1-5]. The use of daylighting may also lead to beneficial reductions in cooling energy, along with possible increases in heating energy [6].

In addition to the effects of daylighting on building energy usage, the building construction and operating costs are influenced by the selection of the building fenestration system. Building designers are faced with the task of determining the optimum fenestration design by evaluating the trade-offs among first cost, energy usage, energy costs and a multitude of other fenestration performance parameters. The optimum fenestration design varies with geographical location, building type, orientation and occupant factors.

While hand calculation procedures, computer programs and nomograms exist for the evaluation of the performance of fenestration systems, little guidance is available regarding the selection of the appropriate fenestration system for the specific application, particularly early in the design process. Thus, even when the building designer is confident that a particular fenestration design has been accurately evaluated, ambiguity remains regarding the relative merit of that design versus the realm of other potential design alternatives. Other than repeated trial-and-error comparisons, there is a general lack of procedures for optimizing fenestration designs.

Fenestration design characteristics, particularly size and type, are intimately linked to overall building design. A building with north-facing clerestories, for example, would be significantly different than a building with south-facing windows. Since the general building design is set early in the design process, effective use of fenestration requires some early evaluation of fenestration trade-offs and performance.

This report describes a prototype simplified design tool which has been developed to demonstrate a method for assisting the building designer in determining an effective fenestration system design. The design tool consists of a software system implemented on a personal computer using a commercial spreadsheet, and is based on the results from numerous computer simulations of the performance of building fenestration systems which have been incorporated into a database.

The buildings included in the original energy simulations were single zone, openplan, box-like structures typical of commercial and industrial facilities. They were single floor with high ceilings and typical internal equipment loads. While the floor area was $335 \mathrm{~m}^{2}\left(3600 \mathrm{ft}^{2}\right)$ the freestanding building had all exterior walls, while the attached building had two exterior walls and two walls shared with adjacent structures. Thus, the attached building was actually $1338 \mathrm{~m}^{2}$ $\left(14,400 \mathrm{ft}^{2}\right)$. 
The design tool allows the user to determine the best fenestration type, size and orientation based on constraints and criteria input by the user, from the results contained in the database. Fenestration designs can be selected based on energy usages, energy costs or peak load considerations. While the fenestration characteristics selected by the design tool are the best in the database, they do not totally define the optimum, or final, fenestration design specification. Rather, they serve as the starting point in the ultimate selection of an actual fenestration system from the world of commercially-available products.

The design tool is intended to point the designer toward an effective fenestration design and eliminate the need to perform numerous detailed computer simulations early in the design process. As a prototype, the design tool is intended to demonstrate a simplified procedure for cataloging and retrieving fenestration performance information. Additional refinements in the design tool might include such items as more geographical locations, more fenestration characteristics and more detailed economic capabilities.

2. Fenestration Performance Trade-offs

The characteristics of the fenestration system influence the energy usage and cost for lighting, heating and cooling. As external conditions change, the fenestration system admits varying amounts of daylight and solar radiation, while allowing thermal heat transfer as driven by the difference in temperature between the outside environment and the building interior. A cooling load results if the net heat gain to the building space, due to solar heat gain, thermal heat transfer, lighting, equipment and occupant loads, is positive. Conversely, a heating load results from a net heat loss. This assumes that the space conditioning system is activated.

The fundamental fenestration trade-off is as follows: A particular fenestration system will have a specific first cost, relative to a solid wall (or roof, in the case of overhead fenestration). Through the years, the building will require energy for lighting, heating and cooling due to the presence of the fenestration system. The energy usage will have a dollar cost associated with it. The lifecycle cost for the fenestration system includes the first cost plus the annual costs, for energy and maintenance. What fenestration system will provide for optimum performance for a specific application?

This question is typically addressed through a series of deterministic evaluations of proposed fenestration systems. In other words, a particular fenestration system is simulated and then compared to other design options which have been similarly evaluated. The difficulty with this approach is that it is time consuming, and does not guarantee that the optimum design will be achieved. Also, a great deal of duplication of effort can occur if similar fenestration systems and buildings are simulated independently, without regard for previous relevant simulation results.

Rather than performing an exhaustive simulation covering a wide range of fenestration systems for each building design exercise, the performance of various fenestration systems can be evaluated on a parametric basis for a range of buildings and conditions, and the results can be complied and made available 
for comparing different fenestration designs for specific building applications. In this regard, a design tool can perform tasks the designer would otherwise be required to do. These would include selecting an appropriate basic fenestration design by searching through the database to find design information from a previously simulated similar building. The design tool would then proceed to optimize the design based on any differences between the previously simulated building and the building of interest, and any other user requirements.

A computer simulation of annual building energy usage will be valid for similar buildings and climatic conditions. The energy cost, however, will vary as the unit cost of energy varies, as it does from region to region and over time. Thus, while energy usage can be determined once and utilized repeatly energy costs must be recomputed for each application based on energy unit cost information provided by the designer. The same is true for the first cost of various fenestration systems. The design tool can provide the specifications and characteristics of the optimum fenestration system. An auxiliary database containing up-to-date energy and fenestration component costs would be required to complete the life cycle cost evaluations.

\section{Determining Optimum Fenestration Design}

Fenestration effectiveness can be evaluated either on the basis of total cost or energy usage, or some combination of both. In the following analysis, only the portion of the cost or energy usage due to the fenestration system is of interest. Thus the total cost associated with the fenestration system consists of the extra cost for the fenestration above the cost of the solid building component, plus the annual differential cost for lighting, heating, cooling and maintenance over the life of the fenestration system. That is:

$$
\$_{I}=\$_{F}+\left(\$_{L}+\$_{H}+\$_{C}+\$_{M}\right) U P W
$$

where: $\quad \$_{\mathrm{T}} \quad=$ total fenestration cost relative to solid wall or ceiling

$$
\begin{aligned}
& \$_{F} \quad=\text { differential first cost of fenestration system } \\
& \$_{\mathrm{L}} \quad=\text { differential annual lighting energy cost } \\
& \$_{\mathrm{H}} \quad=\text { differential annual heating energy cost } \\
& \$_{\mathrm{C}} \quad=\text { differential annual cooling energy cost } \\
& \$_{\mathrm{M}} \quad=\text { differential annual maintenance cost } \\
& \text { UPW } \quad=\text { uniform present worth factor }
\end{aligned}
$$

The two typical cost assessments are payback (PB) and savings-to-investment ratio (SIR). These are defined by: 


$$
\begin{gathered}
P B=\frac{\$_{F}}{-\left(\$_{L}+\$_{H}+\$_{C}+\$_{M}\right)} \\
S I R=\frac{-\left(\$_{L}+\$_{H}+\$_{C}+\$_{M}\right)(U P W)}{\$_{F}}
\end{gathered}
$$

The individual energy costs are given by:

$$
\begin{aligned}
& \$_{\mathrm{L}}=\left(E_{\mathrm{L}}\right)\left(\$_{\mathrm{Lu}}\right) \\
& \$_{\mathrm{H}}=\left(E_{\mathrm{H}}\right)\left(\$_{\mathrm{Hu}}\right) \\
& \$_{\mathrm{L}}=\left(E_{\mathrm{C}}\right)\left(\$_{\mathrm{Cu}}\right)
\end{aligned}
$$

where: $\quad E_{\mathrm{L}}=$ differential annual lighting energy usage

$$
\begin{aligned}
& E_{\mathrm{H}}=\text { differential annual heating energy usage } \\
& \mathrm{E}_{\mathrm{C}}=\text { differential annual cooling energy usage } \\
& \$_{\mathrm{Lu}}=\text { unit cost of lighting energy } \\
& \$_{\mathrm{Hu}}=\text { unit cost of heating energy } \\
& \$_{\mathrm{Cu}}=\text { unit cost of cooling energy }
\end{aligned}
$$

The total energy usage $\left(E_{T}\right)$ is simply the sum of the three energy components:

$$
E_{\mathrm{T}}=E_{\mathrm{L}}+E_{\mathrm{H}}+E_{\mathrm{L}}
$$

The differential energy usages can either be directly calculated by one of various methods, primarily building energy analysis computer programs, or the appropriate values can be selected from compilations of previous energy simulations.

The database used for the design tool described in the present report contains results from an extensive series (640) of simulations for a range of fenestration types, sizes and characteristics, for five geographical locations [7]. Table 1 summarizes the various simulation parameters.

Table $1 \quad$ Summary of Building Simulation Parameters

$$
\text { Geographical Locations }
$$

Boston Norfolk Miami San Diego Seattle 


\author{
Building Type \\ (insulated roof \& walls \\ single floor, open plan \\ industrial or commercial) \\ Fenestration Type \\ (double pane)
}

Fenestration Size

Daylighting
Brick Freestanding

Brick Attached

Metal Freestanding

Metal Attached

None

Skylights

South sawtooth

North sawtooth

South window

North window

Skylights $1,2.25,48$ of

roof area

Sawtooth 5,10,20\% of

roof area

Window $10,20,40 \%$ of window wall

area

Yes, No

The lighting system was modeled as fluorescent with linear dimming to $30 \%$ minimum, at $19.4 \mathrm{KJ} / \mathrm{m} 2(1.8 \mathrm{w} / \mathrm{ft} 2)$. The illumination setpoint was 538 lux (50 fc). Thermostat setpoints were 20 to $25.5^{\circ} \mathrm{C}\left(68\right.$ to $78^{\circ} \mathrm{F}$ ) (deadband).

Table 2 lists the values which have been computed and compiled in the data base for each building simulation. Any of these values can be chosen by the user as the parameter for ranking and selecting the fenestration options contained in the database.

Table 2 Fenestration Performance Values
Annual total energy usage
Annual electric energy usage
Annual heating energy usage
Annual cooling energy usage
Annual electric cost
Annual heating cost
Annual cooling cost
Total annual energy cost
Peak heating load
Peak cooling load

The design tool database contains results which are based on detailed hourly simulations of building energy performance using BLAST and CEL-1 $[8,9,10]$. BLAST was used for the thermal and energy calculations, while CEL-1 provided the lighting and daylighting performance simulations. The combination of the two programs enabled detailed simulation of annual building energy requirements [11].

One limitation of the knowledge base is that it contains results for only five locations. Other locations which may be of interest to the user may not be adequately represented by any of the five simulated locations. One method of 
determining the best location to use would be to compare the heating and cooling degree days for the location of interest to the same for the five simulated location. If the degree days are similar for one simulated location, that location can be selected. If the location of interest falls between two simulated locations, the subsequent analysis can be performed for each location and the results compared. The optimum design can then be determined by interpolation. Table 3 lists the heating and cooling degree days for the knowledge base locations.

Table 3 Heating and Cooling Degree Days for Geographical Locations in Knowledge Base

Base $18.3^{\circ} \mathrm{C}\left(65^{\circ} \mathrm{F}\right)$

Location

Boston

Norfolk

Miami

San Diego

Seattle
Heating Degree Days

$3170(5706)$

1830 (3294)

$82 \quad(147)$

$660(1188)$

3001 (5401)
Cooling Degree Days

389

$2373(4272)$

357 (642)

79 (142)

Other limitations of the knowledge base are lack of a range of U-values and solar heat gain factors. All of the energy usage results assume double-pane, clear glazings without additional shading. Double-pane glazing is the most widely utilized, and clear glass provides maximum daylighting potential. In most cases, if the evaluation results in the selection of a particular fenestration type and size, this result will not be significantly influenced by small differences in U-value.

4. Using the Design Tool

The design tool was implemented on a personal computer using LOTUS-123. A worksheet was developed containing the knowledge base and a series of macros to guide the user through the design process. In order to use the system, the user must have the LOTUS-123 spreadsheet computer program on their computer system. The daylighting design tool worksheet file can then be retrieved and utilized.

From the user's point of view, the daylighting design tool consists of three computer screen displays. The displays contain the instructions needed to manipulate and execute the design tool.

Before proceeding with the evaluation, the user should assemble any information regarding the particular building design and energy unit costs. Default energy unit costs are included in the worksheet, but should be replaced with current costs for the location in question. Since energy costs vary widely over time and with location, it would be impractical to try to include current energy costs in the database.

The user should also select and replace the heating efficiency and cooling coefficient of performance (COP) default values contained in the worksheet, if necessary. The energy simulation results assume a heating efficiency of 0.80 and 
a cooling COP of 3 . If these values are expected to be different, the appropriate ones should be entered on the worksheet.

The analysis is commenced by retrieving the daylighting design tool worksheet, which is a file named DAYEX.WK1. The file is large, so the UNDO feature may need to be disabled first. The first screen of the worksheet will be visible, as shown in figure 1 .

The user can select any combination of the parameters listed, including location, building type, building configuration, fenestration type, fenestration orientation and whether daylighting is used. The user may also enter energy unit costs, heating efficiency and cooling COP, if desired.

Instructions on the screen guide the user in making the selections. For example, to select a location, press ALT and L together. The cursor will move to the location column. Then use the arrow keys to highlight the desired location, followed by RETURN. This process can be repeated for the other parameters. If different energy unit costs, efficiency or COP are to be used, use the arrow keys to highlight the value to be changed, type in the new value and then press return. When all selections have been made, press ALT and G.

The system then performs an initial sort, selecting from the knowledge base all the designs which satisfy the parameters previously selected. These records are extracted, and the second screen is displayed as shown in figure 2. This screen allows the user to select the criterion upon which to rank the design options. The designer might wish to minimize total energy usage, total energy cost or peak cooling loads. Most of the energy and thermal load values are given as ratios. The normalization factors are the energy or thermal loads for an identical building without any fenestration. This allows the relative performance of the fenestration systems to be evaluated. A ratio less than one means less energy is needed than for an identical building without fenestration.

The optimization factor is selected by using the arrow keys to highlight one of the factors, followed by RETURN. At this point the system examines the records previously extracted from the knowledge base and sorts them according to the selected optimization factor. The optimum design, or designs in the case of ties, is then displayed on the third screen, as shown in figure 3. This screen summarizes all of the characteristics and results for the optimum designs.

The results can be printed using ALT $P$, the evaluation can be continued using ALT $M$, or the user can exit the system using ALT Q. If the user elects to continue the evaluation, screen one will reappear and new selections can be made.

Figure 4 shows the results from a sample design session. A daylighted brick building in Norfolk was selected, with the optimization factor being total energy. The design tool determined that a south-facing window with an area of 408 of the wall would provide minimum total energy for the building.

The amount of energy required would be 828 of that required if no fenestration were used. However, cooling energy would be $67 \%$ higher due to solar heat gains. This would be offset by $15 \%$ lower heating energy and $28 \%$ lower electric energy (primarily for lighting). Peak heating loads would be 88 higher and peak cooling 
loads $36 \%$ higher with the $40 \%$ south-facing window than for the baseline bulding with no fenestration. Energy costs and peak load results are also shown.

As a demonstration of how design tradeoffs could be evaluated, the analysis was repeated using cooling energy ratio as the optimization factor. The results are shown in figure 5. The minimum cooling energy is obtained for a north facing sawtooth with an area of $5 \%$ of the roof. Cooling energy is only $74 \%$ of that for the baseline building. Total energy is reduced $7 \%$, and significant reductions in electric energy $(30 \%)$ are apparent. Peak cooling loads are also substantially reduced, due to daylighting.

At this point the user would need to decide what was more important, total energy usage or cooling energy requirements. The answer would vary with the particular design requirements.

As a third option, the least total energy usage was again specified but for sawtooth fenestration. The results are shown in figure 6 . The least total energy for a sawtooth occurs for a south-facing sawtooth with an area of $20 \%$ of the roof. The total energy ratio is $84 \%$. However, cooling energy increases 698 . Thus total energy usage is reduced at the expense of increasing cooling energy.

Similar comparisons can be made on an energy cost basis, or peak load considerations.

\section{Conclusions}

A simplified daylighting design tool was developed and demonstrated for designing and optimizing building fenestration systems. The design tool was implemented on a personal computer using a LOTUS-123 spreadsheet format, and a database containing the results from numerous building energy simulations. Effective fenestration types, sizes and orientations can be determined based on userdefined constraints and requirements such as building type, geographic location and whether daylighting is utilized. Designs can be evaluated and compared based on energy, loads or cost considerations.

In spite of the large number of simulations included in the database, the results are obviously limited to buildings and locations similar to those simulated. It is hoped that as additional results become available, they can be incorporated into the database, or that the format of the design tool worksheet can be used for other databases.

6. References

1. Treado, S., Gillette, G., and Kusuda, T., Evaluation of the Daylighting and Energy Performance of Windows, Skylights and Clerestories, NBSIR 83-2726, National Bureau of Standards, Gaithersburg, MD, June 1983.

2. Kusuda, T., Collins, B., "Simplified Analysis of Thermal and Lighting Characteristics of Windows - Two Case Studies", National Bureau of Standards Building Science Series 109, February 1978.

3. Johnson, R., Selkowitz, S., Winkelman, F., Zentner, M., "Glazing 
Optimization Study for Energy Efficiency in Commercial Office Buildings", Third International Symposium on Energy Conservation in the Built Environment, Dublin, Ireland, March 1982.

4. Jurovics, S., "Daylight, Glazing and Building Energy Minimization", IBM Scientific Center publication, Los Angeles, CA, 1981.

5. Place W., Fontoynant, M., Bauman, F., Anderson, B., Howard, T., "Commercial Building Daylighting", LBLO-14348, Lawrence Berkeley Laboratory, Berkeley, CA 94720,1982 .

6. Treado, S., Holland, D., Bean, J., and Gillette, G., Fenestration Design for Building Atria, NBSIR 87-3594, National Bureau of Standards, Gaithersburg, MD, Sept. 1987.

7. Treado, S., Holland, D., and Remmert, W., Daylighting and Energy Evaluation of Industrial Buildings, NBSIR 85-3241, National Bureau of Standards, Gaithersburg, MD, February, 1986.

8. Hittle, D., "The Building Loads Analysis and System Thermodynamics (BLAST) Program", Version 2.0, Users Manual Vol. 1 and Vol. 2, Technical Report E153/ADA072272 and ADA722730, U.S. Army Construction Engineering Research Laboratory, June 1979.

9. CEL-1 Lighting Computer Program - Programmer's Guide, CR 83.009, Naval Civil Engineering Laboratory, Port Hueneme, CA 93043, January 1983.

10. CEL-1 Lighting Computer Program - User's Guide, CR 81.026, Naval Civil Engineering Laboratory, Port Hueneme, CA 93043, September 1981.

11. Treado, S., Holland, D., Remmert, W., Pierpoint, W., Building Energy Analysis with BLAST and CEL-1, NBSIR 85-3256, National Bureau of Standards, Gaithersburg, MD, February 1986. 
Press and hold Alt key and Letter above category to make selection. After highlighting item, press return key. If you make a mistake just make the selection again, or select a blank if you do not want any choice. Then enter fuel costs, heating efficiency and COP below. MENU

\begin{tabular}{|c|c|c|c|c|c|}
\hline $\begin{array}{l}\text { L } \\
\text { Location }\end{array}$ & $\begin{array}{l}\text { B } \\
\text { Building }\end{array}$ & $\begin{array}{l}\text { C } \\
\text { Configuration }\end{array}$ & $\begin{array}{l}\text { T } \\
\text { Type }\end{array}$ & $\begin{array}{l}0 \\
\text { Orientation }\end{array}$ & $\begin{array}{l}\text { D } \\
\text { Daylighting }\end{array}$ \\
\hline $\begin{array}{l}\text { Boston } \\
\text { Miami } \\
\text { Norfolk }\end{array}$ & $\begin{array}{l}\text { Brick } \\
\text { Metal }\end{array}$ & $\begin{array}{l}\text { Freestd } \\
\text { Attached }\end{array}$ & $\begin{array}{l}\text { Skylights } \\
\text { Sawtooth } \\
\text { Window }\end{array}$ & $\begin{array}{l}\text { North } \\
\text { South }\end{array}$ & $\begin{array}{l}\text { Yes } \\
\text { No }\end{array}$ \\
\hline
\end{tabular}

San Diego

Seattle

Enter electric unit cost $\$ / 60 \mathrm{KJ}(\$ / \mathrm{KWH}): 0.07$ Cooling COP : 2.5 Enter heating unit cost $\$ / 60 \mathrm{KJ}(\$ / \mathrm{KWH}): 0.05$ Efficiency : 0.8

To Continue Press and hold Alt key and G

Figure 1 Screen one of the daylighting design tool 
Now, select optimization factor by highlighting number next to the Menu Item and pressing the return key.

Optimization Menu

1 Total Energy Ratio

2 Heating Energy Ratio

3 Cooling Energy Ratio

4 Electric Energy Ratio

5 Peak Heating Ratio

6 Peak Cooling Ratio

7 Total Energy Cost

8 Heating Energy Cost

9 Cooling Energy Cost

10 Electrical Energy Cost

11 Peak Heating

12 Peak Cooling

Figure 2 Screen two of the daylighting design tool 


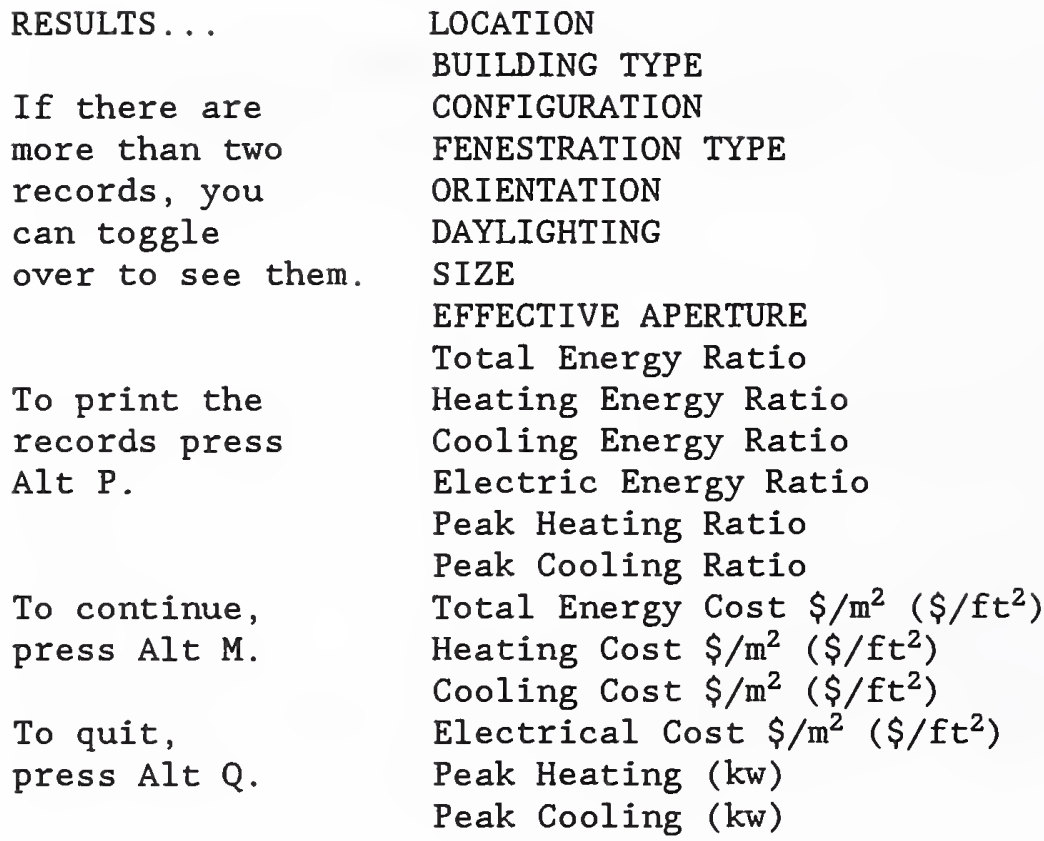

Peak Cooling (kw)

Figure 3 Screen three of the daylighting design tool 


\begin{tabular}{|c|c|c|c|}
\hline RESULTS . . & LOCATION & orfolk & \\
\hline & BUILDING TYPE & Brick & \\
\hline If there are & CONFIGURATION & tached & \\
\hline more than two & FENESTRATION TYPE & Window & \\
\hline records, you & ORIENTATION & South & \\
\hline can toggle & DAYLIGHTING & Yes & \\
\hline over to see them. & SIZE & $40.00 \%$ & \\
\hline & EFFECTIVE APERTURE & 0.32 & \\
\hline & Total Energy Ratio & 0.82 & \\
\hline To print the & Heating Energy Ratio & 0.85 & \\
\hline records press & Cooling Energy Ratio & 1.67 & \\
\hline Alt $\mathrm{P}$. & Electric Energy Ratio & 0.72 & \\
\hline & Peak Heating Ratio & 1.08 & \\
\hline & Peak Cooling Ratio & 1.36 & \\
\hline To continue, & Total Energy Cost $\$ / \mathrm{m}^{2}\left(\$ / \mathrm{ft}^{2}\right)$ & $\$ 0.09$ & $(\$ 1.02)$ \\
\hline press Alt $\mathrm{M}$. & Heating Cost $\$ / \mathrm{m}^{2}\left(\$ / f t^{2}\right)$ & $\$ 0.04$ & $(\$ 0.38)$ \\
\hline & Cooling Cost $\$ / \mathrm{m}^{2}\left(\$ / f t^{2}\right)$ & $\$ 0.01$ & $(\$ 0.15)$ \\
\hline To quit, & Electrical Cost $\$ / \mathrm{m}^{2}\left(\$ / \mathrm{ft}^{2}\right)$ & $\$ 0.05$ & $(\$ 0.49)$ \\
\hline press Alt Q. & Peak Heating ( $\mathrm{kw}$ ) & 34.5 & \\
\hline & Peak Cooling (kw) & 19 & \\
\hline
\end{tabular}

Figure 4 Sample results from design session for Norfolk, minimum total energy 


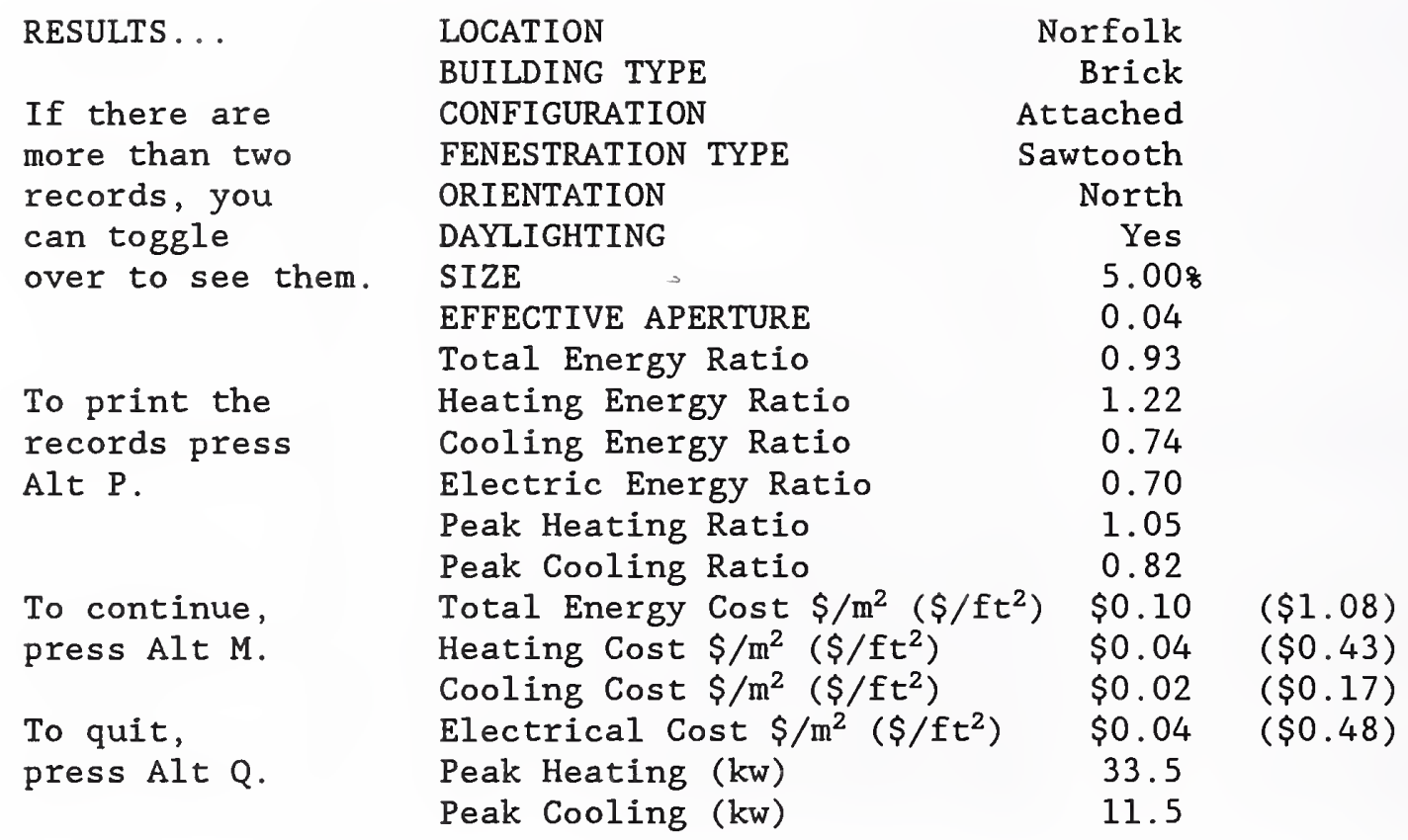

Figure 5 Sample results for Norfolk, minimum cooling energy 


\begin{tabular}{|c|c|c|c|}
\hline RESULTS... & LOCATION & orfolk & \\
\hline If there are & $\begin{array}{l}\text { BUILDING TYPE } \\
\text { CONFIGURATION }\end{array}$ & $\begin{array}{l}\text { Brick } \\
\text { Cached }\end{array}$ & \\
\hline more than two & FENESTRATION TYPE & vtooth & \\
\hline records, you & ORIENTATION & South & \\
\hline can toggle & DAYLIGHTING & Yes & \\
\hline over to see them. & $\begin{array}{l}\text { SIZE } \\
\text { EFFECTIVE APERTURE }\end{array}$ & $\begin{array}{l}20.00 \% \\
0.16\end{array}$ & \\
\hline & Total Energy Ratio & 0.84 & \\
\hline To print the & Heating Energy Ratio & 0.90 & \\
\hline records press & Cooling Energy Ratio & 1.69 & \\
\hline Alt $\mathrm{P}$. & $\begin{array}{l}\text { Electric Energy Ratio } \\
\text { Peak Heating Ratio } \\
\text { Peak Cooling Ratio }\end{array}$ & $\begin{array}{l}0.71 \\
1.13 \\
1.07\end{array}$ & \\
\hline $\begin{array}{l}\text { To continue, } \\
\text { press Alt M. }\end{array}$ & $\begin{array}{l}\text { Total Energy Cost } \$ / \mathrm{m}^{2}\left(\$ / \mathrm{ft}^{2}\right) \\
\text { Heating Cost } \$ / \mathrm{m}^{2}\left(\$ / \mathrm{ft}^{2}\right) \\
\text { Cooling Cost } \$ / \mathrm{m}^{2}\left(\$ / \mathrm{ft}^{2}\right)\end{array}$ & $\begin{array}{l}\$ 0.10 \\
\$ 0.03 \\
\$ 0.04\end{array}$ & $\begin{array}{l}(\$ 1.04) \\
(\$ 0.32) \\
(\$ 0.38)\end{array}$ \\
\hline $\begin{array}{l}\text { To quit, } \\
\text { press Alt Q. }\end{array}$ & $\begin{array}{l}\text { Electrical Cost } \$ / \mathrm{m}^{2}\left(\$ / \mathrm{ft}^{2}\right) \\
\text { Peak Heating }(\mathrm{kw}) \\
\text { Peak Cooling (kw) }\end{array}$ & $\begin{array}{c}\$ 0.05 \\
36 \\
15\end{array}$ & $(\$ 0.49)$ \\
\hline
\end{tabular}

Figure 6 Sample results for Norfolk, north sawtooth, minimum total energy 


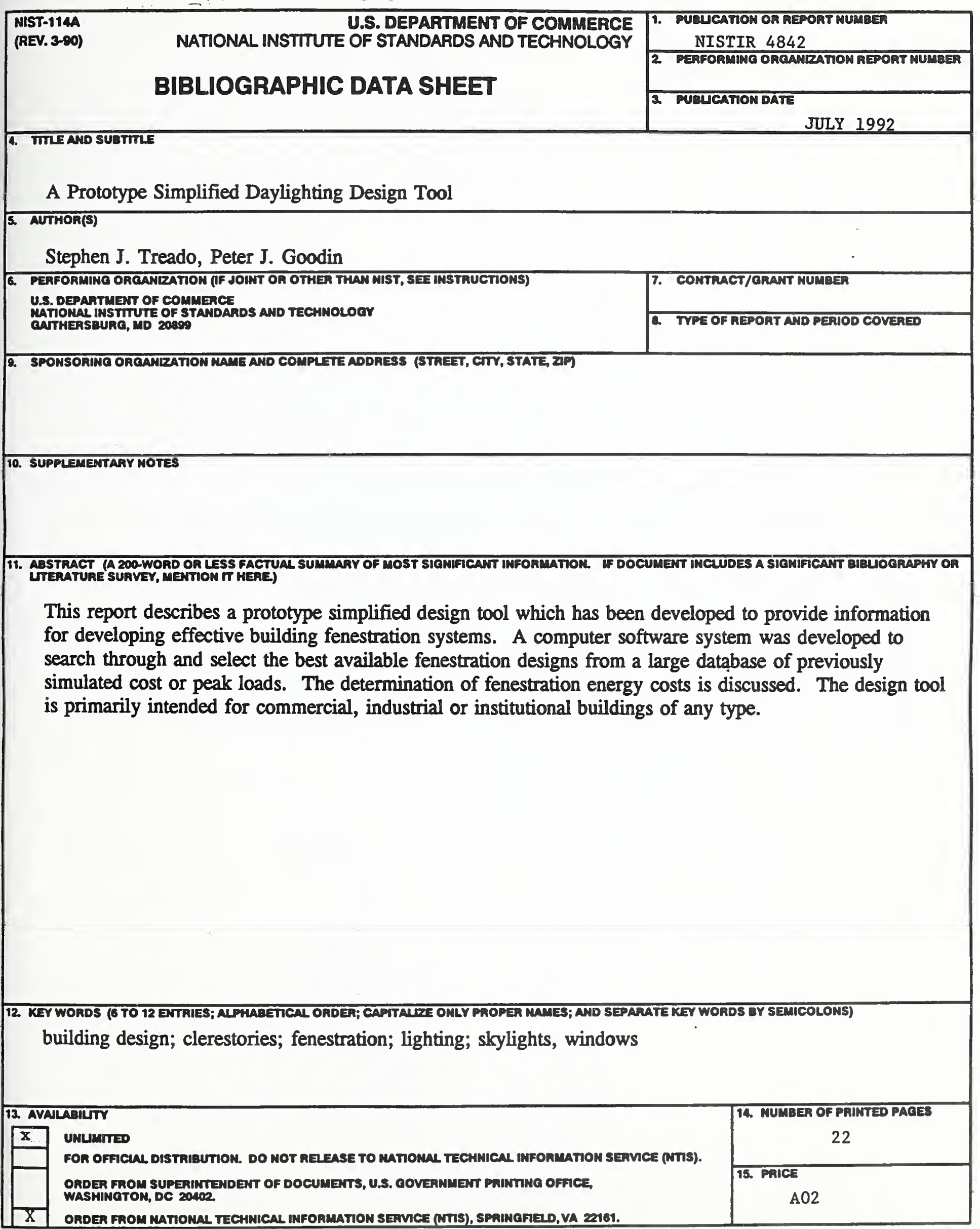




